\title{
A descentralização do poder de decisão nos Relatórios do Desenvolvimento Humano (PNUD/ONU) produzidos no início da década de 2000
}

Decentralization of decision-making power in the Human Development Reports (UNDP/UN) produced in the early 2000s

Se há algo recorrente nos RDHs (Relatórios do Desenvolvimento Humano) que têm sido produzidos anualmente para o PNUD ${ }^{1}$ desde 1990 e visam ser "um exercício em avaliação global de desenvolvimento" (Fukuda-Parr, 2002, p. 3), é a sua insistência na abordagem das capacidades extraída de Amartya Sen $(2008,2010,2011)^{2}$. Essa abordagem tem insistido que no centro do processo de reprodução da pobreza e das desigualdades está a "privação das capacidades" (Sen, 2010, p. 121). Os RDHs têm ressaltado que tanto as desigualdades quanto a inadequação de capacidades devem ser pensadas em vista de uma pluralidade de eixos que governam a vida das pessoas. A ausência de renda e de acesso à saúde e à educação forma os eixos básicos que levam à privação das capacidades. Amartya Sen, no livro Desenvolvimento como liberdade (2010), trabalha detalhadamente por que e como a pobreza deve ser tomada como privação das capacidades:

O que a perspectiva da capacidade faz na análise da pobreza é melhorar o entendimento da natureza e das causas da pobreza e privação desviando a atenção principal

É professora do Departamento de Ciências Sociais da Universidade Estadual de Londrina (Londrina, PR, Brasil).E-mail: mjderezende@gmail.com.

Sakiko Fukuda-Parr (2002), uma das diretoras dos Relatórios do Desenvolvimento Humano desde 1995, faz questão de ressaltar que os RDHs são publicados para o PNUD e não pelo PNUD.

"Os Relatórios do Desenvolvimento Humano (RDHs), publicados anualmente para o PNUD, desde 1990, têm usado o enfoque de Sen sobre capacidade como uma moldura conceitual, na sua análise dos desafios do desenvolvimento contemporâneo" (Fukuda-Parr, 2002, p. 1). 
dos meios (e de um meio específico que geralmente recebe atenção exclusiva, ou seja, a renda) para os fins que as pessoas têm razão para buscar e, correspondente, para as liberdades de poder alcançar esses fins (Sen, 2010, p.123).

Todavia, há, desde os anos iniciais da primeira década do terceiro milênio, uma discussão sobre o modo como esses três eixos têm tornado estreita a abordagem do desenvolvimento humano. No entanto, eles têm se mantido pela inexistência, diz a diretora dos $\mathrm{RDHs}$, de índices de dignidade e de liberdade (Fukuda-Parr, 2002).

O primeiro passo na análise dos $\mathrm{RDHs}$ é não pressupor que suas propostas sejam somente a reiteração das ideias de seus criadores, tais como Mahbud Ul Haq (1978) e Amartya Sen. A própria diretora dos RDHs Fukuda-Parr (2002) faz questão de reiterar que os conceitos de Sen (de desenvolvimento humano, de privação de capacidades e de habilidades, entre outros) emolduram o conjunto de propostas que são feitas, pelos relatórios, anualmente, para combater a privação e a impotência, mas há, por parte dos documentos encomendados pelo PNUD, a intenção de operacionalizar esses conceitos de tal forma que seja possível, de modo propositivo, indicar maneiras de "remover os obstáculos para fazer aquilo que uma pessoa pode fazer na vida. [Obstáculos] tais como analfabetismo, falta de saúde, impossibilidade de acesso a recursos, ou ausência de liberdades civis e políticas" (Fukuda-Parr, 2002, p. 3).

Fukuda-Parr (2002) afirma que o enfoque das necessidades básicas é predecessor da abordagem do Desenvolvimento Humano. Isso indica que não é possível confundir essas duas abordagens. Elas possuem um forte parentesco, porém não são a mesma coisa. A diferença mais relevante entre elas está na abordagem das capacidades. Aquela primeira também tem como pressuposto essencial que todo desenvolvimento deve estar voltado para a melhoria da vida das pessoas, daí a necessidade de expansão da melhoria do bem-estar social. O eixo da Basic Needs é o da comodidade, diz Fukuda-Parr (2002), e não o da capacidade. Sônia Rocha entende que "adotar a abordagem de necessidades básicas insatisfeitas significa ir além daquelas [abordagens fundadas] na alimentação. [A Basic Needs visa] incorporar uma gama mais ampla de necessidades, tais como educação, saneamento e habitação" (Rocha, 2005, p.19). Para ela, o IDH (Índice de Desenvolvimento Humano) é herdeiro direto da abordagem denominada Basic Needs ao 
sintetizar alguns índices sociais assentados na renda, na longevidade e na educação. A busca de índices que fossem capazes de medir as condições de vida e não só de renda era uma preocupação do enfoque Basic Needs desde a década de 1970. Paul Streeten (1982) é um dos mais importantes teóricos do desenvolvimento dentro dessa perspectiva.

Fukuda-Parr (2002) indica um caminho plausível para a análise centrada na abordagem do desenvolvimento humano $(\mathrm{DH})$ que está contida nos relatórios. Ela insiste na necessidade de que seja levado em conta que a $\mathrm{DH}$ possui

duas teses principais sobre pessoas e desenvolvimento e faz distinção entre as mesmas. Elas são o que Sen denomina o "aspecto avaliativo" e o "aspecto da agência”. O primeiro está preocupado com a melhoria das vidas humanas com um objetivo explícito do desenvolvimento e com a compreensão da forma como esse desenvolvimento será efetuado. O segundo, com o que os seres humanos podem fazer para alcançar essas melhorias, particularmente por meio de estabelecimento de estratégias e mudanças políticas. O enfoque de desenvolvimento humano é comumente associado com o aspecto avaliativo. Mas o aspecto da agência é menos apreciado (Fukuda-Parr, 2002, p. 3).

Ao explorar os RDHs, no que diz respeito às suas propostas de descentralização do poder de decisão, observa-se que realmente eles condensam uma preocupação central com a seguinte questão: quais e quem são os agentes impulsionadores do desenvolvimento humano? Todos os relatórios lidam, persistentemente, com a necessidade de definir esses agentes. E os definem em vista de uma perspectiva que lhes dão a certeza de que não há qualquer outro caminho senão aquele que vai ampliando, mais e mais, os agentes impulsionadores das mudanças que levam ao desenvolvimento humano e podem ser tanto individuais quanto coletivos. Esse processo é denominado, nos RDHs, de governança democrática.

Em razão de tal postura, verifica-se que os formuladores dos RDHs estão à procura tanto dos agentes de mudança quanto das ações que eles deveriam empreender para conduzir os países em direção ao desenvolvimento humano. Esse tipo de abordagem não é, de modo algum, novo na sociologia, a qual desde suas primeiras reflexões viu-se às voltas com o desafio de definir os agentes de mudança social. Conforme afirma Piotr Sztompka, os desafios tomaram dimensões cada vez maiores quando na teoria e na prática a "ideia de agência foi estendida para baixo, a todas as pessoas em vez de uns 
poucos eleitos, a todos os papéis sociais e não apenas às funções de poder" (Sztompka, 1998, p. 329).

Como o objeto deste estudo são as práticas e ações sugeridas, pelos RDHs, da década de 2000, ao poder local (entendido aqui como municípios, departamentos, províncias etc. $\left.{ }^{3}\right)$, os problemas sociológicos que norteiam esta investigação são os seguintes: ao sair em defesa, ao longo da década de 2000, da descentralização dos processos decisórios e da necessidade de valorização das instâncias de poder local, os formuladores dos RDHs estão supondo que, no âmbito local, já existem agentes capazes de levar a cabo o desenvolvimento humano e/ou estão defendendo ações que sejam capazes de gerar, a médio e a longo prazo, agentes que poderão atuar para a efetivação desse tipo de desenvolvimento?

O outro problema sociológico é o seguinte: as equipes produtoras dos RDHs insistem na necessidade de abrir canais de participação por onde podem se formar agentes de mudança, mas se observa, na mesma proporção, uma preocupação com as muitas dificuldades, que possuem os diversos grupos, de abrir canais de comunicação ${ }^{4}$ com os diversos agentes incumbidos de levar adiante uma política de desenvolvimento humano capaz de impactar, de fato, a vida dos mais pobres? Os RDHs parecem ou não empenhados em compreender de onde provém essa dificuldade? Pode-se dizer que grande parte das suas dificuldades provém de sua impossibilidade de lidar com as muitas especificidades sociais e políticas que possui cada país em cada região do planeta?

Como esta é uma pesquisa documental, que necessita levar em conta tanto a autoria dos documentos e as condições sociopolíticas, nas quais eles vêm-se tornando públicos, como os objetivos que norteiam as suas publicações por um organismo internacional como as Nações Unidas, deve-se assinalar que cada relatório é produzido por um grupo de técnicos cuja pretensão é dar um enfoque específico aos temas centrais que orientam cada edição dos

São várias as formas de ordenamento político e administrativo local. O Brasil organiza-se como municípios, mas há países na América Latina (a Colômbia, por exemplo) que se organizam, no plano local, como departamentos.

${ }^{4}$ Norbert Elias discute o processo de democratização como um processo de expansão simultânea de canais de participação e de comunicação entre os que possuem e os que não possuem o poder de decisão. Tomados em conjunto são esses dois processos que possibilitam que o poder vá-se inclinando, aos poucos, "a favor daqueles [estratos] que anteriormente" não possuíam qualquer poder (Elias, 1999a, p. 68). 
documentos. Desse modo, deve-se ter sempre em mente que não há uma orientação única, no que diz respeito às muitas temáticas abordadas pelos relatórios, ao longo de mais de 20 anos. Sendo assim, verifica-se que nos RDHs o poder público, por exemplo, é tratado ora como detentor de grandes possibilidades de intervenção nos processos de mudança que levariam ao desenvolvimento humano ora com desconfiança acerca de sua capacidade de ser ainda o agente principal nesse processo. Há relatórios que possuem um tom voltado mais para demonstrar que não se deve esperar que o Estado possa ser tomado como capaz de responder sozinho aos muitos problemas relacionados à pobreza, à educação, à saúde, à habitação e ao saneamento, e há os que insistem em demarcar as tarefas que ainda cabe ao Estado assumir em diversas áreas da vida social.

Por essa razão toda discussão dos RDHs deve tanto considerar o conjunto dos relatórios como um pano de fundo para assinalar quais deles serão mais bem enfatizados. Neste artigo, procurar-se-á ter em conta algumas propostas mais gerais que alinhavam os diversos documentos para situar, no seu interior, as sugestões de descentralização propostas no início da década de 2000. Pretende-se enfatizar esse período, visto que há algo, a partir do ano 2000, que reordenou muitas proposições no interior dos respectivos relatórios: a adoção pelos estados-membros das Nações Unidas da Declaração do milênio (ONU, 2000). Por isso, considera-se relevante realizar uma análise das propostas de descentralização do poder de decisão nos relatórios do início da década de 2000, já que eles estavam tentando responder às exigências postas pelos ODMs (Objetivos do Desenvolvimento do Milênio). Todos os oito objetivos ${ }^{5}$ demandam ações conjuntas do Estado, sociedade civil, associações comunitárias, organizações não governamentais e grupos voluntários.

Seguir-se-á, neste artigo, um percurso a se iniciar com o debate sobre os obstáculos existentes tanto no poder central quanto no poder local para descentralizar os processos decisórios, tentando-se verificar quais são, para os autores dos relatórios, os problemas atinentes às possibilidades, se as há, de os países levarem a cabo uma melhor distribuição do poder entre as diversas instâncias, notando-se que os formuladores dos respectivos docu-

Os Objetivos de Desenvolvimento do Milênio são oito: 1) erradicar a pobreza extrema e a fome; 2) atingir o ensino básico universal; 3) promover a igualdade entre os sexos e a autonomia das mulheres; 4) redução da mortalidade infantil; 5) melhorar a saúde materna; 6) combater o HIV/Aids, a malária, a tuberculose, entre outras doenças; 7) garantir sustentabilidade ambiental; e 8) estabelecer uma parceria mundial para o desenvolvimento. Para entender as metas de cada objetivo, ver ONU (2005). 
mentos fazem uma análise quase sempre bastante ampla, já que, pelo caráter e natureza dos relatórios, há uma dificuldade de eles levarem em conta as muitas singularidades das políticas internas dos diversos países e regiões do mundo. Em seguida, foram feitas as discussões sobre as propostas contidas nos RDHs do início da década de 2000 acerca da descentralização do poder de decisão e dos seus efeitos sobre a ampliação da participação política local.

\section{Descentralização do poder de decisão: os obstáculos que não cessam de desafiar o poder central e o poder local}

No RDH de 2003, cujo título é ODM: um pacto entre nações para eliminar a pobreza humana, assiste-se a uma tentativa, por parte da equipe formuladora, de mostrar quais são os laços entre poder central e poder local para a efetivação dos Objetivos do Desenvolvimento do Milênio (ODMs). O desafio da trasladação do poder de decisão para os municípios, departamentos, comunidades, entre outros, toma uma parte expressiva das discussões sobre as possibilidades de criar, por meio da participação, estímulos para modos de agir democráticos. A descentralização seria, então, uma forma de gerar atitudes e/ou disponibilidades para um agir mais voltado à execução, planejamento e apoio àquelas medidas que levem ao cumprimento dos ODMs.

Pode-se dizer que a questão da descentralização das decisões políticas, no interior dos RDHs, foi-se tornando mais e mais complexa no decorrer da década de 1990 e da de 2000. Isso porque os relatórios passam a lidar, após a Declaração do milênio (ONU, 2000), com desafios mais bem definidos nos diversos campos, sejam eles sociais, econômicos, políticos ou educacionais, entre outros. Os ODMs têm como característica básica o fato de que a sua viabilização depende de um envolvimento extenso não somente dos governantes mas também da sociedade civil e de todos os grupos organizados e/ou com potencialidade de organização. Isso levou os formuladores dos RDHs a construir, desde o RDH de 2001, uma forte correlação entre o cumprimento dos ODMs e o fortalecimento de processos decisórios no âmbito local. A equipe que gerou o RDH de 2003 faz a seguinte afirmação: "Grupos da sociedade civil - desde organizações comunitárias a associações profissionais, passando por grupos de mulheres e redes de organizações não governamentais (ONG) - têm um papel importante na ajuda à execução e acompanhamento do progresso em direção aos Objetivos [ODMs]" (PNUD/ ONU, 2003, p. 2). 
Há, segundo os técnicos que produziram o RDH de 2003, enormes desafios postos ao cumprimento dos ODMs. Entre eles estão aqueles relacionados às dificuldades dos estados nacionais serem capazes e eficientes para se voltarem à efetivação de políticas que levem ao desenvolvimento humano. Segundo ele, não há outra forma de sustentar políticas que conduzam ao cumprimento dos ODMs senão a que conta com uma mobilização popular que faça progredir e dê sustentação a uma determinação obstinada de atingir melhorias sociais que impactem, de fato, a vida dos mais pobres. "Essa mobilização popular exige culturas políticas abertas e participativas" (PNUD/ONU, 2003, p. 2).

É interessante cotejar esse discurso presente nos RDHs com diversos outros que são produzidos entre intelectuais e lideranças políticas diversas. $\mathrm{Na}$ década de 2000, muitos intelectuais (Boaventura de Sousa Santos e todo o grupo que está presente na obra Democratizar a democracia, por exemplo) têm defendido a necessidade de repolitizar a discussão sobre o desenvolvimento. Não se trata de uma recusa do tema, mas sim da defesa de uma nova abordagem. Eé interessante notar como muitas posições que defendem a repolitização acabam esbarrando com as mesmas questões postas pelos RDHs. D. L. Sheth, do Centro de Estudos sobre Desenvolvimento, na Índia, afirma que é necessário "encarar o desenvolvimento como uma luta política para a participação das pessoas na definição dos objetivos do desenvolvimento e no planejamento dos meios para atingi-los" (Sheth, 2002, p. 103).

$\mathrm{Na}$ verdade, é nisso que os elaboradores dos RDHs estão insistindo de modo incisivo. Todavia, há uma diferença entre a perspectiva posta por Sheth e a abraçada pelos técnicos dos RDHs. E qual é? Enquanto a abordagem da qual faz parte o cientista social indiano insiste que a repolitização passa pela rejeição de qualquer tentativa de criar uma perspectiva hegemônica do desenvolvimento, os elaboradores dos RDHs estão incumbidos de criar uma visão hegemônica do desenvolvimento humano. Todo o debate sobre participação, descentralização, fortalecimento do poder local, comunitário etc. expressa uma tentativa de encontrar um caminho, ainda que não inteiramente padronizado, que seja possível aos diversos povos seguir.

Deve-se perguntar: o que seria supor uma via não hegemônica de desenvolvimento? Seria, segundo Sheth, supor a geração de um caminho que se fosse constituindo não a partir de um receituário predeterminado, mas sim por articulações e conhecimentos próprios gerados durante o processo de 
organização e participação, dos diversos grupos sociais, em busca do desenvolvimento. Isso significa, em última instância, que nem os cientistas sociais, nem os organismos internacionais e seus técnicos, nem os governantes, nem as lideranças da sociedade civil poderiam, de antemão, indicar quaisquer caminhos a seguir. Todavia, as coisas não se passam dessa maneira, pois o conhecimento sobre os processos de desenvolvimento é uma construção de longa duração que tenta operacionalizar a relação entre a teoria e a prática. A pergunta seria: quando e como, de fato, o conhecimento e a prática em busca do desenvolvimento é anti-hegemônico? Assim, a proposta presente nos RDHs de descentralização, de participação popular, de mobilização é hegemônica ou anti-hegemônica?

Se o empenho para chegar ao desenvolvimento anti-hegemônico deve estar composto da participação de uma gama de pessoas, grupos, associações, lideranças da sociedade civil, entre outros, e se todos eles devem, conjuntamente, construir tanto os objetivos a serem atingidos como o planejamento de ações que articulem conhecimentos produzidos no interior desses grupos, pode-se dizer que os múltiplos grupos que formulam, anualmente, os RDHs não poderiam ser considerados como propositores de um desenvolvimento anti-hegemônico. Isso porque eles buscam, sim, definir alguns pilares básicos do que seria reconhecido como desenvolvimento humano. Entre eles estão os seguintes: a formação de capacidades, de habilidades profissionais e políticas, de igualdade de oportunidades e de observância dos direitos humanos. Todas as ações devem caminhar no sentido de fazer com que a privação e a impotência sejam combatidas a partir da viabilização de inúmeras atividades que contemplem o que está definido naqueles pilares fundamentais.

A ideia central de desenvolvimento anti-hegemônico, defendida por alguns intelectuais (Boaventura de Sousa Santos, D. L. Sheth, Patrick Heller ${ }^{6}$, T. Thomas Isaac ${ }^{7}$, entre outros) é "a alteração da relação de poder na sociedade" (Sheth, 2002, p. 104). Os elaboradores dos RDHs insistem nessa alteração todo o tempo, todavia eles não deixam suficientemente claro até onde deveria ir essa alteração. Nos RDHs de 2002 e 2003, parece que eles propõem reformas na relação de poder, o que pode significar mudanças expressivas naquelas sociedades com poder de decisão totalmente concentrado.

Professor-investigador na Brown University, Estados Unidos. Ver Heller e Isaac (2002).

Investigador no Centro de Estudos sobre Desenvolvimento da Índia. 
D. L. Sheth (2002, p. 104) afirma que essa proposta de desenvolvimento anti-hegemônico, pautada na convicção de que o desenvolvimento é um processo político, ganhava substancialidade à medida que "as instituições de desenvolvimento global [iam] desistindo, aberta e oficialmente, da antiga promessa de universalizar o desenvolvimento para todos". Soa bastante estranha essa afirmação, já que, desde 1990, o Programa para o Desenvolvimento das Nações Unidas mostrava-se empenhado em reelaborar uma promessa universal de desenvolvimento não pautada somente no PIB (Produto Interno Bruto), no progresso tecnológico e na renda per capita, a qual passava, a partir dali, a ser denominada de desenvolvimento humano ${ }^{8}$. Na verdade, não houve essa desistência ${ }^{9}$. E disso tem consciência o próprio cientista social Sheth (2004) que produziu um paper regional para o RDH de 2004. É possível supor, então, que para ele os $\mathrm{RDH}$ tinham um caráter distinto, ou seja, esse de elaborar proposições de desenvolvimento que levavam em conta as especificidades regionais e locais.

A equipe produtora do RDH de 2003 dá prosseguimento a essa convicção de que o desenvolvimento humano só é, de fato, alcançado, pelas diversas sociedades, se ocorrer uma redefinição das relações de poder. Todo o debate sobre descentralização do poder de decisão indica isso. Entretanto, ela fala em expansão do número de agentes participantes nas decisões que favorecem a luta contra a privação e a impotência, mas não sai em defesa de uma reestruturação radical das relações de poder. Envidar esforços comunitários em favor do cumprimento dos ODMs, por exemplo, poderia ser, conforme dizem os produtores do RDH de 2003, um caminho para "estimular debates democráticos acerca do desempenho do governo" (PNUD/ONU, 2003, p. 2). Isso motivaria o envolvimento de vários segmentos com as questões relacionadas ao combate à pobreza absoluta, ao analfabetismo, à mortalidade de crianças e de mães etc.. Esse seria um primeiro passo para um envolvimento maior das populações locais com as decisões políticas que afetam a vida dos mais pobres.

Mas a descentralização é difícil. Para ter êxito, precisa de uma autoridade central capaz, de autoridades locais empenhadas e com poder financeiro e de cidadãos empenhados numa sociedade civil bem organizada. Em Moçambique, autoridades locais

8 O embate político sobre desenvolvimento sustentável é outra vertente das muitas propostas de desenvolvimento, no final do século XX, que intencionam abarcar o mundo como um todo. Ver Sachs (2002, 2004).

9 Sobre a influência global da proposta de desenvolvimento humano, ver Sen (2010). 
empenhadas e com capacidade financeira aumentaram a cobertura de vacinação e as consultas pré-natal em $80 \%$, vencendo limitações de capacidade através da contratação de Organizações Não-Governamentais (ONG) e de fornecedores privados a nível municipal. Experiências recentes também mostram como os movimentos sociais podem levar a uma tomada de decisão mais participativa, como na monitorização pública dos orçamentos locais. Em Porto Alegre, no Brasil, essa monitorização trouxe enormes melhorias aos serviços. Em 1989, pouco menos de metade dos habitantes da cidade tinha acesso a água potável. Sete anos mais tarde, quase todos tinham. A escolarização primária também duplicou durante esse período e os transportes expandiram-se a zonas afastadas (PNUD/ONU, 2003, p. 3).

Um dado que vem à tona nesse trecho do relatório é a defesa do estabelecimento de parcerias entre o poder público, o poder privado e as ONGs. Quando os técnicos mencionam o respaldo da sociedade civil organizada, o documento reitera suas propostas que vêm ganhando corpo desde 1990: as de que a sociedade civil deve desenvolver a capacidade política de compreender o que pode ser realizado pelo Estado e o que é necessário compartilhar com outros setores. Deve-se, segundo eles, trasladar parte do poder para o âmbito local a fim de que assim fique mais viável o entendimento tanto da execução das políticas sociais que devem ser partilhadas entre poder público, poder privado, ONGs e grupos voluntários quanto das formas possíveis de controle e de fiscalização desse tipo de operação.

Observe-se que os movimentos sociais são destacados também como agentes dotados de capacidade participativa na monitorização pública do modo de emprego de recursos nas políticas de melhoria da educação, da saúde, do acesso à água potável e ao saneamento. "Esse tipo de ação coletiva melhora os serviços básicos e ajuda a estimular e sustentar a vontade política. Cidadãos comuns pressionam os seus líderes para cumprirem os seus compromissos políticos" (PNUD/ONU, 2003, p. 2).

Defendem uma melhor divisão do poder entre os diversos grupos sociais da seguinte maneira: o empenho deve caminhar no sentido de ampliar o poder entre aqueles que não o têm, o que não significa, necessariamente, que, assim, será possível subtrair uma parcela expressiva de poder das mãos de determinados segmentos que, durante séculos, concentraram, em suas mãos, muito poder.

Talvez seja possível fazer a seguinte comparação: da mesma forma que A. Sen (2001) afirma que o grande desafio posto ao desenvolvimento humano 
é aumentar a renda dos mais pobres e não diminuir a renda dos mais ricos, também os técnicos dos RDHs lançam-se, muito mais, numa busca de meios para ampliar o poder de decisão dos segmentos destituídos de poder do que na defesa da diminuição do poder daqueles segmentos que detêm, de fato, na atualidade, poderes altamente concentrados, tais como os que controlam o capital financeiro e o capital tecnológico (ver Furtado, 1998, 2002). José Eli da Veiga faz a seguinte afirmação sobre isso:

Não se percebe [hoje] qualquer propensão a encarar as necessárias 'grandes transformações estruturais das economias e das sociedades. Isto é, as transformações globais e nacionais de caráter redistributivo que nenhum setor da ONU, da OCDE, do FMI ou do BIRD ousaria sugerir ou aconselhar. Afinal esse é o maior tabu das relações internacionais, apesar das evidências de que as desigualdades atrofiam o bem-estar (Veiga, 2011, p. 3).

\section{Os RDHs do início da década de 2000 e as propostas de fortalecimento das instâncias locais de decisão}

O RDH de 2000 insiste que o Estado tem de "executar políticas que ajudem a realização dos direitos sociais e econômicos em benefício dos mais desfavorecidos" (PNUD/ONU, 2000, p. 77, tradução nossa). É fundamental observar que esse tipo de consideração deve ser lido no decorrer do embate político sobre o papel do Estado que estava em voga nas décadas de 1990 e 2000. Esse embate impactou consideravelmente as propostas sobre o que cabia, nas diversas instâncias, ao Estado realizar. O papel do poder local, entendido aqui como municípios e/ou departamentos, passa a ser problematizado, enfaticamente, no âmbito dos Relatórios do Desenvolvimento Humano. A ênfase na expansão das capacidades tenta conectar os canais de participação e os de comunicação entre os diversos grupos sociais ${ }^{10}$. O que significa, então, capacitar, para os formuladores dos RDHs? Ao discutir a melhoria da capacidade das mulheres eles insistem na necessidade de "aumentar a visibilidade das mulheres em posições de autoridade e de tomada de decisão local e nacional" (PNUD/ONU, 2003, p. 86). Eles enfatizam:

\footnotetext{
10 Seria interessante, num outro artigo, fazer uma reflexão sobre o modo como tem sido feita, no Brasil, essa conexão entre os canais de participação e de comunicação. Caberia estabelecer um paralelo entre as discussões postas pelos formuladores dos RDHs e as levantadas pelos cientistas sociais acerca dos processos de descentralização do poder de decisão no Brasil.
} 
Capacitar as mulheres exige políticas que tratem tanto das necessidades práticas (apoiar as capacidades básicas necessárias para funcionar, tais como a melhoria das condições de vida e o aumento da oferta de emprego, cuidados de saúde e abastecimento de água potável) como das necessidades básicas (reforçar a voz e a ação das mulheres para renegociarem os seus papéis em casa e na sociedade, tais como os direitos legais e ativos e leis que assegurem salários iguais, direitos de reprodução e ausência de violência). Além disso, estas políticas devem ser apoiadas por leis que garantam direitos iguais - tanto para as mulheres como para os homens, nos setores privado e público (PNUD/ONU, 2003, p. 86).

Deve-se assinalar que, ao chamar a atenção para a responsabilidade do poder público em adotar "políticas para erradicar a pobreza" (PNUD/ONU, 2000, p. 79), políticas de expansão das capacidades dos diversos agrupamentos e políticas de melhoria da educação, os elaboradores dos RDHs, da década de 2000, não estão pressupondo uma supremacia do Estado nesse processo. Bastante influenciados pelos debates acerca do que cabe e do que não cabe às instâncias públicas realizar, eles chamam, seguidamente, a atenção para o fato de que a inegável responsabilidade do Estado é uma coisa, e a suposição de que essa responsabilidade de combate à privação e à impotência é só do Estado, é algo diferente. Para eles, “a erradicação da pobreza depende das ações dos agentes privados das atividades empresariais e da sociedade civil, a saber, as comunidades, as famílias, os sindicatos, os empregadores, as organizações não governamentais, os grupos religiosos e outros" (PNUD/ ONU, 2000, p. 79, tradução nossa).

Se a efetivação dos direitos sociais depende, ao menos em parte, do Estado, como afirma o RDH de 2000, é, então, necessário, segundo ele, distribuir a competência de adoção e execução de políticas para eliminar a pobreza absoluta entre as diversas instâncias governamentais (nacional e local). Todavia, os documentos encomendados pelo PNUD insistem que muitos países têm condições de realizar políticas capazes de erradicar a pobreza, mas não o fazem em razão das dificuldades de redefinir suas políticas econômicas tanto no âmbito nacional como no local. Nesse e em outros casos, os técnicos que produziram os RDHs têm insistido na importância que possuem as lideranças comunitárias para "ajudar a gerar respostas localmente aceitáveis" para os muitos problemas sociais (PNUD/ONU, 2003, p. 99). Muitas políticas, principalmente na área de saúde, para serem viáveis, têm de saber como 
lidar com comportamentos e valores bastante diversificados. As lideranças comunitárias podem, mais facilmente, ajudar a planejar e gerir algumas medidas. Isso para que haja menor rejeição e recusa possível.

O relatório de 2000 chama a atenção para as dificuldades políticas de reorganizar a alocação de recursos de modo a vencer os interesses políticos e econômicos petrificados nas diversas instâncias de poder. Os elaboradores do $\mathrm{RDH}$ de 2000 reconhecem que o problema da alocação de recursos é, essencialmente, político. Não somente político, mas preponderantemente político. Isso leva à necessidade de descentralizar os processos decisórios.

No entanto, é visível um nó nas proposições dos formuladores dos $\mathrm{RDHs}$ da década de 2000: por um lado, a descentralização política e administrativa depende da formação de agentes políticos com capacidade de ação junto aos processos de decisão, por outro, a constituição de tais agentes depende da descentralização. Assim, tal descentralização depende da existência de agentes capazes de reivindicar um espaço político nos processos de decisão. Enquanto não existem tais agentes não há descentralização política possível. Mas, ao mesmo tempo, os proponentes dos relatórios insistem que é possível operacionalizar diversas mudanças nas ações governamentais até que esta descentralização seja, de fato, possível.

Fazer responsáveis os governos é um requisito básico de bom governo. Para isso se requer que o povo esteja organizado e informado e que seja capaz de reivindicar um espaço político. Requer-se ademais descentralização de funções das autoridades locais e transparência no uso dos fundos públicos (PNUD/ONU, 2000, p. 78, tradução nossa).

Nota-se que há no documento acima insistência na simultaneidade de dois processos: a descentralização de funções decisórias e a formação de um espaço político de reivindicação e construção das demandas. Ainda que se saiba que os técnicos que produzem os RDHs não estejam voltados para a discussão de como tais processos poderiam se dar em contextos específicos, pode-se dizer que essa discussão sobre as práticas e procedimentos capazes de fazer avançar as formas de distribuição do poder estiveram presentes em vários países do continente latino-americano. No Brasil, nas décadas de 1970, 1980 e 1990, esse debate, entre intelectuais e lideranças da sociedade civil, sobre como produzir simultaneamente mudanças democráticas nas instituições, nas pessoas, nos grupos, nas organizações populares, entre 
outros, foi muito expressivo (Cohn, 1992; Jacobi, 1995; Souza, 1996; 2001 e 2004; Paoli e Telles, 2000).

Os produtores dos relatórios, em vários momentos (ver, por exemplo, os relatórios PNUD/ONU de 2000, 2002 e 2003), tecem vários comentários favoráveis aos procedimentos participativos oriundos dos Conselhos Populares, do Orçamento Participativo, entre outros. O RDH de 2000 (p. 118) destacava a positividade da pressão da sociedade civil sobre os governantes, pois só assim estes poderiam abraçar, de modo duradouro, a causa do desenvolvimento humano. Em diversos momentos, os relatórios da primeira década do século XXI mencionavam a importância do papel proativo, em várias áreas, da sociedade civil no Brasil. Observa-se que, para os elaboradores dos documentos em análise, o Brasil vinha desenvolvendo importantes canais de participação. Entre esses canais o Orçamento Participativo ganhava destaque. Sobre este último eles afirmavam:

O financiamento municipal foi redistribuído para financiar intervenções nas áreas pobres da cidade. O sistema de transportes foi alargado para abranger as zonas mais remotas. A qualidade e alcance das obras e serviços públicos - tais como a pavimentação de estradas, construção de habitação social e projetos de desenvolvimento urbano - sofreram uma melhoria significativa. Muitos bairros miseráveis foram urbanizados. O déficit de meios de pavimentação das ruas foi eliminado. E a corrupção foi reduzida. O elevado grau de envolvimento da sociedade civil e a mudança de atitude das autoridades políticas foram extremamente vantajosos para a criação de consensos e para a tomada de decisões. Os representantes das 16 divisões administrativas da cidade reúnem-se duas vezes por ano em assembléias plenárias para discutir as questões orçamentais. Estes eventos são coordenados conjuntamente pelo executivo municipal e por representantes da comunidade, e os participantes incluem executivos, (...) administradores, representantes de associações de moradores, jovens e clubes desportivos, e quaisquer outros moradores interessados (PNUD/ONU, 2003, p. 143).

Por essas e outras razões, os produtores dos RDHs de 2003 insistiam que, entre os países que tentaram implantar a descentralização, o Brasil havia tido êxito, assim como a Colômbia, a Jordânia e a África do Sul. Isso teria levado à formação de "respostas rápidas às necessidades locais" (PNUD/ONU, 2003, p. 135). Em várias partes desse documento é mencionado que o Brasil deveria ser tomado como exemplo de sucesso nos processos de participação 
e de descentralização. Alguns investigadores brasileiros, ao longo da década de 2000, tinham também esse entendimento.

Já no final do século XX e início do novo milênio, as organizações da sociedade civil e os movimentos sociais passam a valorizar cada vez mais formas de participação institucional (audiências públicas, assembleias e conferências políticas, fóruns, conselhos setoriais de políticas públicas, orçamento participativo, Agenda 21, etc.). Tais organizações percebem, nesses espaços, a oportunidade do exercício do "controle social pela cidadania", considerado como um meio político adequado e legítimo para a expansão da democracia (Scherer-Warren, 2008, p. 506).

As experiências de deliberação participativa, desde o início dos anos 1980, no Brasil, estão associadas à capacidade que os movimentos sociais tiveram de explicitar demandas relacionadas principalmente com a distribuição de bens públicos e também, em menor escala, na formulação de políticas públicas (Jacobi, 2003, p. 316).

Não há dúvida de que os formuladores dos RDHs herdaram, desse debate acadêmico, conhecimentos acerca das possibilidades e impossibilidades de fazer avançarem mudanças democráticas substantivas no âmbito nacional e local. Nota-se que eles prosseguem, na década de 2000, insistindo, quase sempre, nas possibilidades de viabilização, nos países em geral, de um processo de melhor distribuição do poder. E fazem isso destacando que é possível ser otimista quanto às possibilidades de constituição de novos agentes investidos da capacidade de intervenção nas políticas de erradicação da pobreza absoluta e de combate à privação e à impotência.

Muitos países estão tomando a iniciativa para facilitar a participação e a prestação de contas. A autoridade nacional de desenvolvimento econômico das Filipinas seleciona grupos da sociedade civil para que supervisionem os programas do governo. E organismos da Índia põem à disposição da população os documentos públicos e realizam audiências públicas para institucionalizar a cooperação (PNUD/ONU, 2000, p. 78, tradução nossa).

De modo bastante prático, os produtores do RDH de 2000 consideram que deve partir dos dirigentes a iniciativa de dar transparência às políticas governamentais. Os diversos grupos populacionais devem ser chamados para examinar contas, fundos e investimentos em políticas de combate à 
privação e à impotência. Observe-se que, nessa passagem do documento, há, segundo eles, grupos da sociedade civil preparados para essa incumbência fiscalizadora das ações dos governantes. Há, em alguns outros momentos, a insistência dos elaboradores dos RDHs na necessidade de constituir, de formar, esses agentes.

Os construtores dos documentos encomendados pelo PNUD partem, desde a década de 1990, do pressuposto de que no âmbito local (municípios, departamentos) é muito mais viável e exequível o desenvolvimento de políticas de controle sobre as verbas públicas, de ações capazes de fazer frutificar demandas por melhorias nas áreas de habitação, educação, saneamento e saúde. Em várias passagens, as equipes formuladoras dos RDHs parecem ter certeza de que as mudanças capazes de combater a privação e a impotência devem partir da atuação de agentes locais dotados de capacidade para construir demandas que pressionem também o poder público e o poder privado, ambos locais.

Ainda que as equipes técnicas incumbidas de produzir os RDHs sejam distintas em cada relatório, e alguns indivíduos estejam presentes em equipes diferentes, é visível que alguns elementos condutores atravessam os 21 relatórios publicados entre 1990 e 2011 . Entre esses elementos está a valorização da descentralização do poder para fortalecer as capacidades e habilidades políticas no âmbito local. Praticamente em todos os relatórios está pressuposto que uma melhor distribuição do poder que alcance os municípios, departamentos, comunidades, aldeias etc. seria capaz de impulsionar o desenvolvimento humano. A proximidade entre as lideranças políticas locais, os governantes, os segmentos organizados da sociedade civil e a população de modo geral é vista, pelos elaboradores dos RDHS, como algo que pode fazer prosperarem as melhorias dos serviços sociais básicos e as políticas de combate à privação e à impotência, já que os agentes organizados da sociedade civil, os movimentos sociais e os conselhos municipais possuem a chance de ter uma melhor visualização de como se detectam os problemas e se realizam os planos e os programas para resolvê-los.

Tanto durante a década de 1990 (PNUD/ONU, 1990, 1991, 1992, 1993, 1994, 1995, 1996, 1997, 1998, 1999) como no decorrer da década de 2000, os RDHs (PNUD/ONU, 2000, 2002, 2003, 2004, 2005, 2009, 2010) apresentam certa dubiedade quanto à existência, no plano local, de agentes capazes de construir ações em favor do desenvolvimento humano. Ora parece que 
esses agentes já existem em vários países, ora esses agentes deverão ainda ser criados, ser formados. Mas a maioria das propostas de descentralização política e decisória pressupõe a existência de alguns grupos aptos a fazer prosperarem procedimentos que redefiniriam a vida política como um todo e mudariam o padrão de intervenção do poder público na área social. A descentralização político-administrativa seria um primeiro passo na visão dos formuladores do relatório. Desse modo, pergunta-se: há, ou não, uma aposta na possibilidade de sensibilizar as elites locais para que elas, uma vez no poder, trabalhem em prol de uma melhor distribuição de recursos e de poder?

Em alguns momentos parece que sim, pois, mesmo em sociedades onde não há um espaço público construído nem um enfrentamento político entre diversos grupos e agentes e movimentos políticos organizados no interior da sociedade civil, os realizadores do $\mathrm{RDH}$ de 2002 consideram possível construir processos descentralizadores do poder de decisão. Então, se estes podem preceder a existência de agentes politicamente organizados e capacitados para impulsionar uma melhor distribuição de poder é porque os técnicos que produziram os relatórios supõem que é possível que os agentes governamentais sejam impelidos a caminhar rumo a uma melhor distribuição de recursos e poder. No RDH de 2002, há ênfase no modo como, muitas vezes, as elites locais distorcem, a seu favor, todo e qualquer processo de mudança. Há relatos nos documentos de como isso tem sido recorrente nos vários continentes.

Uma solução para tais problemas é descentralizar o poder em favor dos níveis inferiores de governo, aproximando-o mais da população. Mas os funcionários locais não são mais imunes à influencia das minorias privilegiadas que os funcionários do governo central. Em efeito, longe de fortalecer a democracia local, a descentralização pode em realidade reforçar o poder e a influência das minorias privilegiadas locais. Em tais circunstancias, os cidadãos podem ter mais sorte com funcionários que estejam mais longe. Um estudo recente de 12 países indicou que em somente a metade deles havia alguma prova, às vezes bem limitada por certo, de que a descentralização habilita mais gente, reduz a pobreza, aumenta o progresso social ou mitiga a desigualdade espacial. A descentralização ajuda mais os pobres quando a política local é democrática, com estruturas sólidas e práticas de participação abertas. A descentralização só pode potencializar as pessoas comuns se vai acompanhada por um forte apoio aos grupos comunitários (PNUD/ONU, 2002, p. 67, tradução nossa). 
A preocupação recorrente nos relatórios diz respeito, então, à maneira como as pessoas comuns podem ou não ser beneficiadas por um processo de descentralização que, de modo horizontal, e não vertical, construiria algumas mudanças na condução do poder público e na sua articulação com o poder privado. Não havendo habilidade, capacidade e oportunidade política para que aqueles que estão fora da contenda possam entrar, não dá para visualizar como as pessoas de modo geral poderiam ser ouvidas e inseridas nesse processo de descentralização política. Acredita-se que isso é um nó difícil de desfazer no interior dos RDHs.

No Brasil, Celso Furtado (1964, 1992, 1997, 1998, 1999, 2002), em diversos textos, demonstrou o quanto é ilusório imaginar que as elites locais tenham algum interesse em operar qualquer forma de descentralização do poder decisório. A seu ver, todo e qualquer processo nesse sentido teria de ser construído simultaneamente a partir de reformas estruturais que levassem à democratização do Estado como um todo e ao fortalecimento das organizações da sociedade civil (sindicatos, associações e organizações que congregassem os diversos interesses) que viessem a se enfrentar na arena política. Ao participar da contenda, os diversos grupos sociais estariam construindo formas de uma melhor distribuição de poder. Em A fantasia desfeita (1997), Furtado mostrava que não havia outra maneira de ocorrer qualquer processo de distribuição do poder e de descentralização.

Os elaboradores do $\mathrm{RDH}$ de 2002 tentam ser otimistas em relação à possibilidade de que processos de descentralização gerados por grupos que estão no poder possam refletir, positivamente, na vida dos indivíduos mais pobres, os quais poderão, pouco a pouco, segundo consta nos documentos, ir-se inserindo na arena política e construindo, ainda que lentamente, alguma forma de participação. Todavia, esse otimismo vem seguidamente eivado de muitas desconfianças ao assumir que, mesmo com algumas reformas democráticas e com algumas intrusões das pessoas comuns nos processos decisórios, "as minorias privilegiadas mantêm o poder estatal e prevalecem as estruturas de poder desiguais" (PNUD/ONU, 2002, p. 69).

Um mérito do RDH de 2002, assim como de outros, é retratar, com certas minúcias, o quão difícil é construir processos de descentralização para que haja uma melhor distribuição do poder entre os diversos grupos sociais. Há, por parte dos técnicos, uma exposição detalhada acerca das incertezas que atravessam toda e qualquer tentativa de distribuição de poder. Os documen- 
tos deixam claro que não é possível saber, com certeza, se os mais pobres, por exemplo, serão ou não beneficiados de fato. Norbert Elias (1994, 1998, 1999) diz que a construção de melhores equilíbrios de poder tem tido, ao longo da história, essa característica de incerteza quanto aos resultados e ao alcance, real, de tais processos.

É possível verificar que os formuladores dos RDHs tentam apagar as incertezas por meio de uma exageração das possibilidades de fortalecimento, nas diversas partes do mundo, de um poder público local que seja capaz de ir sendo direcionado, mais e mais, em favor dos mais pobres. Há algo ambíguo que pode ser descrito da seguinte maneira: numa dimensão mais profunda, é visível que os técnicos põem em evidência o quanto os processos de descentralização e de democratização do poder público local é difícil e tortuoso, mas, numa dimensão mais superficial, numa leitura mais rápida dos documentos, pode ficar também a impressão de que não é tão difícil, tão complicado, caminhar rumo à construção de uma maior democratização. O otimismo de alguns trechos pode, às vezes, soterrar as passagens do texto que revelam o quanto é difícil que ocorram, nos diversos países da América Latina, Ásia, África e Oceania, processos de distribuição de poder em favor daqueles segmentos inteiramente destituídos de qualquer posição de poder.

Em princípio, o poder de descentralização do centro para as províncias, os distritos ou as aldeias, permite que a população participe mais diretamente na tomada de decisões. Mas na prática pode simplesmente transferir o poder de um grupo da elite a outro. A descentralização democrática, que verdadeiramente outorgue voz à população, exige algo mais que a mera descentralização (...) do poder. Também exige ampliação da participação, especialmente por parte das pessoas que amiúdo se veem marginalizadas, tais como as mulheres, as minorias e os pobres (PNUD/ONUI, 2002, p. 74, tradução nossa).

Essa passagem do documento põe em evidência que os técnicos produtores dos relatórios encomendados pelo PNUD supõem que a descentralização do poder é a geradora da possibilidade de ampliação dos agentes que deverão participar no processo de efetivação do desenvolvimento humano. Nota-se, então, que a descentralização pressupõe a existência de alguma participação já constituída; há, portanto, nesse caso, alguns agentes dotados de habilidade e capacidade de participação. A trasladação do poder para o 
âmbito local aparece nos RDHs como a resposta mais eficaz para a ampliação tanto da participação como do número de agentes envolvidos. Essa suposição acerca de uma via de mão dupla entre descentralização e ampliação da participação e do número de agentes, por parte dos construtores dos relatórios, pode ter viabilidade em algumas partes do Hemisfério Sul, mas não tem em inúmeros países. Isso porque em muitas regiões do mundo não se verifica a existência de um lastro participativo capaz de sustentar um processo de descentralização que, de fato, fosse capaz de distribuir poder e de construir canais de comunicação efetivos entre os que governam e os demais setores da sociedade. Conforme diz Norbert Elias (1999, 1998, 2006), os impulsos a favor da democratização ocorrem, de fato, se além dos canais de participação forem também abertos canais de comunicação entre os diversos segmentos sociais.

A equipe que formulou o RDH de 2002 parece considerar que tais canais podem ser detectados em alguns países e que as suas experiências devem servir como referência para outras medidas descentralizadoras. Ela afirma:

A Bolívia oferece (...) exemplo interessante de descentralização democrática. Sua lei de participação popular, de 1994, ampliou a participação política e descentralizou as decisões em matéria fiscal. Em virtude da lei se criaram municípios em zonas rurais onde anteriormente não havia presença oficial do Estado. Reconheceram-se oficialmente as organizações comunitárias locais. Reduziram-se as desigualdades mediante uma redistribuição dos recursos fiscais baseada na densidade da população. E se conferiu mais poder aos governos locais, descentralizando a infraestrutura física dos serviços de atenção saúde, educação, redes viárias, sistemas de irrigação e atividades culturais. As organizações comunitárias desempenham papel-chave: a lei estabelece procedimentos que lhes permitem formular propostas para satisfazer as necessidades municipais e supervisionar os serviços e projetos do governo local (PNUD/ONU, 2002, p. 75, tradução nossa).

Todas essas considerações sobre o processo de descentralização, após 1994, na Bolívia devem ser lidas à luz das especificidades daquele país que, segundo Fernanda Wanderley (2010), possui uma polarização política entre duas visões de como deve se organizar a sociedade e o Estado. Uma é liberal e a outra é estadista comunitária. No RDH de 2002 tem-se a impressão de que os técnicos que confeccionaram o documento estão em 
defesa de uma experiência comunitária, porém sem sair em defesa da responsabilização do Estado como agente único nem em defesa do fim dessa responsabilização na implantação de medidas que levem ao processo de desenvolvimento humano. Quando se debruça sobre as condições sociais de países (a Bolívia, por exemplo) que estão impregnados "historicamente por relações clientelistas e corporativas entre o Estado e a sociedade e por altos níveis de corrupção institucional” (Wanderley, 2010, p. 44), fica realmente muito difícil visualizar como novos agentes surgirão e se manterão firmes na reivindicação de novos equilíbrios e deslocamentos de poder. $\mathrm{Na}$ América Latina têm sido frequentes as estratégias que impedem que novos agentes adentrem a arena política. Isso visa impedir que eles possam reivindicar posições de poder.

O grupo que elaborou o $\mathrm{RDH}$ de 2002, não obstante ser otimista com as possibilidades políticas de experiências descentralizadoras como esta da Lei de Participação Popular da Bolívia ${ }^{11}$, de 1994, destaca que as reformas atingiram, de modo distinto, as diversas comunidades. Umas ter-se-iam beneficiado, mas outras não. Carlos Lopes e Thomas Theisohn, ambos do PNUD/ONU, fazem uma discussão sobre a Lei de Participação Popular (LPP), de 1994. Eles defendem a positividade da referida lei em razão de que ela determinava a transparência na prestação de contas em todos os níveis governamentais (Lopes e Theisohn, 2006). A reforma político-administrativa estabeleceu que os conselhos municipais fossem ativos no processo de planejamento e execução de programas de desenvolvimento. A LPP é vista pelos autores como um norte importante para o combate à pobreza no âmbito local.

Os produtores desse relatório de 20002 expõem algumas críticas à respectiva lei acima mencionada.

Alguns críticos dizem que as organizações locais são muito heterogêneas e desorganizadas, e soterram outras organizações da sociedade civil, tais como os sindicatos, que representam os interesses da população. Outros dizem que as elites ainda podem "sequestrar" o processo. Dizem que, se a lei tivesse estado acompanhada por medidas para reestruturar a política dos partidos locais e para reprimir drasticamente a corrupção local, suas repercussões haveriam sido melhores. (...) Apesar de tudo isso, essa iniciativa inovadora tem incorporado a ação dos grupos da sociedade civil, [o

1 Sobre essa lei, ver ainda PIEB (2006). 
que tem levado] mais claramente à governabilidade local e [à] prática democrática (PNUD/ONU, 2002, p. 75, tradução nossa).

Entre vários exemplos dados pelo RDH de 2002 sobre a importância dos processos de descentralização, está o Decreto de Democracia Popular, de 1998, no Vietnã, que definia ações que mantivessem informada a população sobre recursos, orçamentos e planejamento de gastos. O documento do PNUD demonstra que esse decreto foi resultado das organizações, em âmbito local, dos agricultores insatisfeitos com a forma de alocação dos recursos orçamentários locais. "Também esboça esferas em que a população local deve discutir (...) as decisões do governo antes que estas sejam adotadas" (PNUD/RDH, 2002, p. 75).

Observe-se que o grupo encarregado de produzir o relatório de 2002, cujo título é Aprofundar a democracia num mundo fragmentado, mostra-se atento às críticas que questionavam o discurso global de uma democracia de mercado e defendiam a ampliação da democracia participativa. Assim como na obra Democratizar a democracia, organizada por Boaventura de Sousa Santos (2002), aparecem o relato e a análise de muitas experiências, ao redor do mundo, de micromovimentos que indicavam a elaboração de novas formas de democracia participativa (Sheth, 2002); também no RDH de 2002, no capítulo 3 intitulado "Aprofundamento da democracia ao fazer frente aos déficits democráticos”, os técnicos buscam várias experiências, vários micromovimentos que estariam indicando possibilidades de desenvolvimento de alguns deslocamentos de poder em favor dos grupos, até então, destituídos de poder.

Há diferenças entre os relatos e análises dessas experiências que aparecem no livro organizado por Boaventura de Sousa Santos (2002) e os que são mencionados nos RDHs. Uma diferença significativa é que estes últimos não estão confrontando tais experiências com o processo de globalização. Eles mencionam as ações descentralizadoras como forma de positivar ações locais capazes de reordenar, ao menos em parte, a política e a administração pública em favor do desenvolvimento humano nos diversos recônditos do planeta. Mas não há dúvida de que existam pontos de aproximação e de distanciamentos entre o enfoque dado pelos cientistas sociais que compõem a coletânea acima mencionada e os técnicos do RDH de 2002. 


\section{Participação no âmbito local como forma de desenvolvimento de controle popular sobre recursos e execução dos serviços sociais básicos}

O capítulo 7 do RDH de 2003 traz uma ampla discussão sobre a necessária mobilização do apoio popular para alcançar os Objetivos do Milênio. Todavia, não era visto como possível que os ODMs fossem atingidos se também as lideranças políticas não baseassem suas ações, seus programas partidários e de governo naquilo que havia sido acordado entre 189 países na Declaração do milênio, em setembro de 2000. Do mesmo modo que em outros relatórios anteriores, a equipe preparadora desse documento insistia na necessidade de que o comprometimento com as mudanças rumo ao desenvolvimento humano se desse em dois âmbitos (no das instituições e no dos demais níveis da sociedade como um todo) que se desdobravam em vários outros. Veja-se o que foi dito: "Os lideres políticos deverão basear-se nos Objetivos ao definirem os seus programas partidários e as suas estratégias eleitorais e os eleitores deverão poder avaliar o desempenho dos seus líderes com base nos progressos alcançados” (PNUD/ONU, 2003, p. 133).

Dentro de seu caráter propositivo e enaltecedor das medidas que indicavam a possibilidade de que os governantes tivessem, aos poucos, assumido o desafio de contemplar, em suas estratégias de governo, as melhorias nas áreas da saúde, da educação, do combate à fome, à mortalidade infantil e materna e à pobreza absoluta, e no acesso à água e ao saneamento, entre outras, o relatório de 2003 citava Camboja, Níger, Chile, Brasil, Paraguai, Albânia, Polônia e Quênia como alguns países que estavam tentando dar alguns passos rumo ao que indicavam os ODMs.

No entanto, esses primeiros passos tinham que ser acompanhados, segundo o documento, de uma ampla mobilização de diversos segmentos sociais de que resultasse uma participação política mais efetiva e que conseguisse, ao menos em parte, desconcentrar o poder político. Os setores populares tinham que ser não só habilitados politicamente mas também dotados da capacidade de construir demandas que contemplassem os interesses dos setores mais pobres. Os elaboradores do RDH de 2003 afirmavam: “(...) nas sociedades desiguais, o progresso em direção aos ODMs é dominado pelas elites e raramente beneficia os mais pobres. Para além do mais, o progresso global de um país pode ocultar o fato de uma grande parte da sua população 
estar a ser deixada para trás, como tem sucedido no Brasil, China, Índia e outros locais" (PNUD/ONU, 2003, p. 134).

Desse modo, os realizadores do documento encomendado pelo PNUD passam a demonstrar que o grande desafio é reverter às injustiças sociais. Focam-se eles, então, em algo que tem sido discutido durante anos por cientistas sociais, lideranças comunitárias, movimentos sociais, entre outros: a necessidade de ampliar a participação para que haja algum tipo de distribuição do poder. Habilidade e capacidade política são o norte das propostas de descentralização. Observe-se o que afirma a equipe do RDH de 2003:

Para reverter [as] injustiças, é essencial que haja pressão política e que as pessoas façam ouvir as suas exigências junto dos seus dirigentes. Porém, mesmo que os recursos sejam afetados de outra forma e que a pressão política seja bem sucedida, existe ainda o risco de não serem criados os mecanismos que permitam a sua execução eficaz. Os serviços públicos básicos mais importantes para a satisfação das necessidades básicas dos mais pobres - centro de saúde, escolas, bombas de água, condutas e poços - são habitualmente geridos por burocratas e funcionários públicos, que apenas respondem perante os seus superiores dentro da hierarquia vertical dos respectivos ministérios. Se, em contrapartida, respondessem perante organismos municipais eleitos a nível local, a prestação destes serviços seria certamente mais eficaz. Para que haja respostas eficazes e adequadas, são necessários incentivos - e formas de controle - locais (PNUD/ONU, 2003, p. 134).

Essa passagem demonstra que há preocupação com as dificuldades de construir canais de comunicação entre os dirigentes e os demais envolvidos. Insiste-se que a reversão das injustiças depende de tais canais. Toca-se, então, numa das maiores dificuldades da vida política atual. Há quem diga (Bauman, 1999; 2000, por exemplo) que é esse o maior desafio para todos os países e não somente para os mais pobres e desiguais. Pode-se verificar, e os RDHs ajudam nessa tarefa, que, nos países com desigualdades enormes em todas as áreas (renda, educação, acesso à saúde, à justiça, etc.), os bloqueios participativos são potencializados pela surdez dos grupos que estão no poder em relação ao que reivindicam os demais.

É interessante indagar se é possível aos formuladores dos RDHs - dada a natureza desse tipo de documento, que é de caráter amplo e sem possibilidade de se debruçar sobre as especificidades de cada país - explorar as condições de sedimentação das dificuldades de constituição de processos participativos e 
de comunicação entre os que governam e os que são governados. Dificilmente eles teriam como explorar profundamente os obstáculos que bloqueiam a constituição de um espaço público capaz de mobilizar ações que levariam mais e mais indivíduos a se capacitarem e a se habilitarem politicamente. Contudo, eles levantam, no RDH de 2003, alguns desafios e possibilidades de mobilizar o apoio popular para o cumprimento dos ODMs. Eles não possuem instrumentais para, com uma lupa, examinar se existem, ou não, as condições, em todos os países, dos diversos continentes, para mobilizar, desde o âmbito local, um número cada vez maior de pessoas aptas a envidar esforços na reivindicação, controle e fiscalização das ações governamentais em favor do desenvolvimento humano.

Há ainda outra questão trazida pelos relatórios. Após demonstrar que se tem assistido, em muitas partes do mundo, a algum processo de descentralização que envolve "a transferência de parte da autoridade política da administração central para as entidades locais” (PNUD/ONU, 2003, p. 134), o documento de 2003 traz a seguinte indagação: "Será que a descentralização do poder e do acesso aos recursos contribui para melhorar a situação dos mais pobres?" (PNUD/ONU, 2003, p. 135).

A equipe do relatório afirma que onde houve descentralização político-administrativa é possível verificar, sim, alguns avanços. Mas admite que os dados são poucos ainda. Há um quadro, na p. 141, do cap. 7, do RDH de 2003, que, de um lado, traz dados sobre a ausência de informações suficientes sobre vários países, e, de outro, detectam-se ainda naqueles países sobre os quais há dados, tanto uma fraca participação dos mais pobres na vida política quanto uma fragilidade dos impactos da descentralização sobre a pobreza social e econômica.

O documento cita alguns sucessos constatados em Botswana, Brasil, Colômbia, Jordânia, África do Sul e Índia. Quais seriam os êxitos?

Respostas mais rápidas às necessidades locais (...). A descentralização proporciona às mulheres a possibilidade de participação política a nível local, permitindo uma abordagem mais sensível ao gênero do processo de decisão e execução política. (...) Os programas de saúde pública passam a ser mais amplamente utilizados, uma vez que os conselheiros locais são mais capazes, do que os burocratas da administração central, de explicar a racionalidade desses programas de uma forma mais compreensível para as populações locais (PNUD/ONU, 2003, p. 135-6). 
O relatório em questão enfatiza ainda que os processos de descentralização do poder têm proporcionado mais transparência e menor corrupção, melhor implementação e manutenção de serviços sociais básicos e de projetos sustentáveis. Vale assinalar que os elaboradores do RDH de 2003 afirmam que tem sido possível constatar que, no âmbito local, há maior possibilidade de solucionar conflitos que comprometem a unidade nacional. Eles assinalam que tem sido constatado que na Etiópia, na África do Sul e na Namíbia, a descentralização ajudou a combater as desigualdades regionais (PNUD/ONU, 2003, p. 136) e isso propiciou melhorias mais amplas naquelas sociedades.

Trasladar para o âmbito local uma parcela expressiva do poder decisório tem sido demonstrado pelos relatórios como uma forma de motivar os grupos locais a "encontrarem solução para os seus problemas cotidianos", o que pode conduzir à redefinição do quadro de representação política. Grupos até então afastados das atividades políticas passam a se enxergar como capazes de disputar posições de poder e de atuar politicamente em favor dos interesses que representam. O RDH de 2003 afirma que isso foi possível verificar na Bolívia (com os Quechua e Aymara), nas Filipinas (com os Kalinga e Gaddang) e no Mali (com os Songhai).

Observa-se, então, que consta no relatório de 2003 que a descentralização é impulsionadora da formação de agentes hábeis e capacitados politicamente. Todavia, nem toda trasladação de poder para o âmbito local é eficiente.

A descentralização tende a ser bem sucedida, quando o governo central é estável (...) e empenhado na transferência de responsabilidades e recursos, quando as autoridades locais têm a capacidade de assumir essas responsabilidades e quando existe uma participação real dos mais pobres e de uma sociedade civil bem organizada. Geralmente, estas condições resultam em políticas e serviços responsáveis, aumento do crescimento, da equidade e do desenvolvimento humano (PNUD/ONU, 2003, p. 138).

Não há dúvida de que, se existirem todas essas condições, o processo de participação será amplo e ampliável. Será também possível que se construam canais efetivos de comunicação entre os diversos segmentos sociais. No entanto, deve-se perguntar: onde, falando principalmente dos países em que campeiam todas as formas de desigualdades, existem tais condições apontadas no trecho acima do RDH de 2003? Há ainda outra questão que também merece ser ressaltada. Esse documento traz uma afirmação queleva a 
entender que, para os seus formuladores, não há, até o presente momento, na maioria dos países com amplas faixas populacionais e que vivem em situação de pobreza absoluta e de extremas desigualdades, condições de efetuação de uma descentralização capaz de levar aos resultados exigidos pelas políticas de efetivação do desenvolvimento humano fundadas na participação e na mobilização popular.

Os três aspectos, tidos como essenciais para o desenvolvimento humano, não estão presentes na maioria dos países do Hemisfério Sul. E quais são eles? "Capacidade efetiva do Estado, autoridades locais competentes, empenhadas e capacitadas, e cidadãos e sociedade civil engajados, informados e bem organizados" (PNUD/ONU, 2003, p. 139).

\section{Considerações finais}

A análise dos RDHs do início da década de 2000 mostrou que prevalece, no seu interior, a ideia de que o surgimento de agentes capazes de intervir na implantação de políticas de fiscalização e de controle dos serviços sociais básicos que beneficiem os mais pobres só é possível se os governantes e as instituições favorecerem a geração da participação, da habilitação e da capacitação. Todavia, em alguns momentos, os RDHs parecem crer que, de algum modo, ainda que embrionário, em algumas sociedades existam alguns agentes que têm de ser impulsionados a tornarem-se mais firmes em suas demandas e reivindicação. Mas fica subentendido que os processos de habilitação e de capacitação política são demorados. No entanto, neles têm de apostar os governantes, a sociedade civil, os movimentos sociais, já que não há, para impulsionar o desenvolvimento humano, outro caminho a não ser o da valorização da ação política reivindicativa.

As dificuldades de construir canais de participação ficam evidentes nos RDHs da primeira metade da década de 2000. Como eles estão voltados para sugerir ações e estratégias que façam vingar os objetivos constantes na Declaração do milênio, faz-se necessário alertar os governantes, a sociedade civil e os movimentos sociais acerca da impossibilidade de cumprir os ODMs sem que haja um processo de desconcentração do poder de decisão. A insistência nesse tipo de procedimento leva a crer que é esse o único caminho possível, naquelas sociedades caracterizadas por processos políticos calcados na expressiva concentração de poder nas mãos das elites econômicas e políticas. 
Gerar habilidade e capacidade política participativa é o norte das propostas contidas nos RDHs desde a década de 1990. Contudo, pode-se dizer que, na década de 2000, as sugestões de trasladação do poder para o âmbito local vão-se esbarrando em algo que os relatórios têm contemplado muito menos: as dificuldades de criar canais afetivos de comunicação além dos canais de participação. Uma real democratização dos procedimentos políticos e administrativos na esfera local supõe que haja a possibilidade de os diversos segmentos serem, de fato, ouvidos e levados em conta pelos governantes. A ausência de canais de comunicação entre os dirigentes e aqueles que são atingidos pelas suas ações é, sem dúvida, o que potencializa o déficit democrático nos países onde prevalecem maiores índices de desigualdades.

Tem-se a impressão, muitas vezes, de que os elaboradores dos relatórios pressupõem que, ao abrir canais de participação, são abertos também canais de comunicação entre os diversos segmentos sociais - o que não ocorre necessariamente. Há países, da América Latina, por exemplo, nos quais os bloqueios participativos são imensos, mas tem-se observado, no decorrer das últimas décadas, que abrir canais de comunicação entre governados e governantes é ainda mais difícil. Habilitação e capacitação política para participar já é uma tarefa titânica; imagine-se, então, para o estabelecimento de uma comunicação política democrática entre os que detêm o poder e os que sofrem as consequências das ações tomadas por eles.

Talvez, sejam esses os maiores desafios postos às propostas de descentralização do poder de decisão. A transferência do poder ao âmbito local acompanhada de fiscalização e controle dos agentes organizados para reivindicar a execução de políticas que levem ao combate da pobreza absoluta, em particular, e ao desenvolvimento humano, em geral, se vê, então, obstruída, num primeiro plano, pelas dificuldades da participação e, num segundo, pelas impossibilidades de construção de canais de comunicação duradouros entre os que detêm o poder e os demais segmentos sociais.

\section{Referências}

BAUMAN, Zygmunt (1999). Globalização: as consequências humanas. Rio de Janeiro: Jorge Zahar. (2000). Em busca da política. Rio de Janeiro: Jorge Zahar.

COHN, Amélia (1992). "Descentralização, cidadania e saúde”. São Paulo em Perspectiva, v. 6, n. 4, p. 70-76. 
ELIAS, Norbert (1994). A sociedade dos indivíduos. Rio de Janeiro: Jorge Zahar.

(1998). Envolvimento e alienação. Rio de Janeiro: Bertrand Brasil. (1999). Introdução à sociologia. Lisboa: Edições 70. (2006). Escritos \& ensaios. Rio de Janeiro: Jorge Zahar.

FUKUDA-PARR, Sakiko (2002). “Operacionalizando as ideias de Amartya Sen sobre capacidades, desenvolvimento, liberdade e direitos humanos: o deslocamento do foco das políticas de abordagem do desenvolvimento humano”. Disponível em: http://www.soo.sdr.sc.gov.br/index. php? option=com_content\&task=view\&id=108\&Itemid=206. Acessado em 07 nov. 2013.

FURTADO, Celso (1964). Dialética do desenvolvimento. Rio de Janeiro: Fundo de Cultura.

(1992). Brasil, a construção interrompida. São Paulo: Paz e Terra. (1997). “A fantasia desfeita”, em Obra autobiográfica. São Paulo: Paz e Terra.

(1998). O capitalismo global. Rio de Janeiro: Paz e Terra.

(1999). “A reconstrução do Brasil". Praga: Revista de Estudos Marxistas, n. 8, p. 9-13.

(2002). Em busca de novo modelo. Rio de Janeiro: Paz e Terra.

HELLER, Patrick \& ISAAC, Thomas, T. M. (2002). “O perfil político e institucional da democracia participativa: lições de Kerala, Índia”, em SANTOS, Boaventura de Sousa (org.) Democratizar a democracia. Rio de Janeiro: Civilização Brasileira.

JACOBI, Pedro (1995). "Alcances y limites de los gobiernos locales progresistas en Brasil: las alcaldías petistas". Revista Mexicana de Sociología, vol. 57, n. 2, p. 143-162.

(2003). "Espaços públicos e práticas participativas na gestão do meio ambiente". Sociedade e Estado, v. 18, n. 1/2, p. 137-154.

LOPES, Carlos \& THEISOHN, Thomas (2006). Desenvolvimento para céticos. São Paulo: Editora Unesp.

ONU (2000). Declaração do milênio. Disponível em: http://www.unric.org/ html/portuguese/uninfo/DecdoMil.pdf. Acessado em 30 mai. 2013.

ONU (2005) Objetivos de Desarrollo del Milênio: Uma mirada desde América Latina y Caribe. Disponível em: http://www.eclac.org/ publicaciones/xml/1/21541/lcg2331e.pdf. Acessado em 26 nov. 2013. 
PAOLI, Maria Célia \& TELLES, Vera L. (2000). "Direitos sociais: conflitos e negociações no Brasil contemporâneo”, em ALVAREZ, Sonia E. et al. (orgs.). Cultura e política nos movimentos sociais Latino-americanos. Belo Horizonte: Editora UFMG.

PIEB (2006). Descentralización, construcción ciudadana y capital social en Bolivia. Disponível em: http://www.pieb.org/participacion/archivos/ Informe_final_PIEB_V4.pdf. Acessado em 19 dez. 2012.

PNUD/ONU (1990): Informe sobre desarrollo humano 1990: Definición y medición del desarrollo humano. Disponível em: http://hdr.undp.org/ en/reports/global/hdr1990/chapters/spanish. Acessado em 4 jun. 2012.

(1991): Informe sobre desarrollo humano 1991: Financiación del desarrollo humano. Disponível em: http://hdr.undp.org/en/reports/ global/hdr1991/chapters/spanish. Acessado em 20 set. 2012.

(1992): Informe sobre desarrollo humano 1992: Una nueva visión sobre desarrollo humano internacional. Disponível em: http://hdr.undp. org/en/reports/global/hdr1992/chapters/spanish. Acessado em 22 jun. 2012.

(1993): Informe sobre desarrollo humano 1993: Participación popular. Disponível em: http://hdr.undp.org/en/reports/global/hdr1993/ chapters/spanish. Acessado em 10 ago. 2012.

(1994): Informe sobre desarrollo humano 1994: Un programa para la Cumbre Mundial sobre desarrollo social. Disponível em: http://hdr. undp.org/en/reports/global/hdr1994/chapters/spanish. Acessado em 12 out. 2012.

(1995): Informe sobre desarrollo humano 1995: La revolución hacia la igualdad en la condición de los sexos. Disponível em: http://hdr. undp.org/en/reports/global/hdr1995/chapters/spanish. Acessado em 02 jul.2012.

(1996): Informe sobre desarrollo humano 1996: ¿Crecimiento económico para propiciar el desarrollo humano? Disponível em: http:// hdr.undp.org/en/reports/global/hdr1996/chapters/spanish. Acessado em 20 ago. 2012.

(1997): Informe sobre desarrollo humano 1997: Desarrollo humano para erradicar la pobreza. Disponível em: http://hdr.undp.org/en/reports/ global/hdr1997/chapters/spanish. Acessado em 22 out. 2012 (1998): Informe sobre desarrollo humano 1998: Cambiar las pautas 
actuales de consumo para el desarrollo humano del futuro. Disponível em: http://hdr.undp.org/en/reports/global/hdr1998/chapters/spanish. Acessado em 22 out.2012

(1999): Informe sobre desarrollo humano: La mundialización con rostro humano. Disponível em: http://hdr.undp.org/en/reports/global/ hdr1999/chapters/spanish. Acessado em 22 out. de 2012

(2000). Informe sobre desarrollo humano: Derechos humanos $y$ desarrollo humano. Disponível em: http://hdr.undp.org/en/reports/ global/hdr2000/chapters/spanish. Acessado em: 11 jan. 2012.

(2002). Informe sobre desarrollo humano 2002: Profundizar la democracia en un mundo fragmentado. Disponível em: http://hdr.undp. org/en/reports/global/hdr2002. Acessado em 02 dez. 2012.

(2003): Relatório do Desenvolvimento Humano: Objetivos de Desenvolvimento do Milênio: Um pacto entre nações para eliminar a pobreza humana. Disponível em: http://hdr.undp.org/en/reports/global/ hdr2003/chapters/portuguese. Acessado em 11 jan. 2013

(2004): Relatório do Desenvolvimento Humano: Liberdade cultural num mundo diversificado. Disponível em: http://hdr.undp.org/en/ reports/global/hdr2004/chapters/portuguese. Acessado em 09 set. 2013.

(2005): Relatório do Desenvolvimento Humano: Cooperação internacional numa encruzilhada: ajuda, comércio e segurança num mundo desigual. Disponível em: http://hdr.undp.org/en/reports/global/hdr2005/ chapters/portuguese. Acessado em 08 set. 2013.

(2009): Relatório do Desenvolvimento Humano: Ultrapassar barreiras: mobilidade e desenvolvimento humanos. Disponível em: http:// hdr.undp.org/en/reports/global/hdr2009/chapters/portuguese. Acessado em 02 jan. 2013

(2010): Relatório do Desenvolvimento Humano: A verdadeira riqueza das nações: caminhos do desenvolvimento humano. Disponível em: http://hdr.undp.org/en/reports/global/hdr2010/chapters/pt. Acessado em 02 out. 2013.

ROCHA, Sônia (2005). Pobreza no Brasil: afinal do que se trata? Rio de Janeiro: FGV.

SACHS, Ignacy (2002). Caminhos para o desenvolvimento sustentável. Rio de Janeiro: Garamond.

(2004). Desenvolvimento: includente, sustentável, sustentado. Rio 
de Janeiro: Garamond.

SCHERER-WARREN, Ilse (2008). "Redes de movimentos sociais na América Latina: caminhos para uma política emancipatória?”. Caderno $\mathrm{CRH}$, v. 21, n. 54 , p. 505-517.

SEN, Amartya (2001). Roda Viva. São Paulo, TV Cultura, 22 jan. Disponível em: http://www.rodaviva.fapesp.br/materia_busca/32/amartya/entrevistados/amartya_sen_2001.htm. Acessado em 02 out. 2012.

(2008). Desigualdade reexaminada. Rio de Janeiro: Record.

(2010). Desenvolvimento como liberdade. São Paulo: Companhia das Letras.

(2011). A ideia de justiça. São Paulo: Companhia das letras.

SHETH, D. L. (2002). "Micromovimentos na Índia: para uma nova política de democracia participativa”, em SANTOS, Boaventura de Sousa (org.). Democratizar a democracia. Rio de Janeiro: Civilização Brasileira.

(2004). "Caste, ethnicity and exclusion in South Asia: the role of affirmative action policies in building inclusive societies". Human Development Report Office background paper for HDR 2004. Disponível em: http://hdr.undp.org/en/reports/global/hdr2004/papers/HDR2004_ DL_Sheth.pdf. Acessado em 26 dez. 21012.

SOUZA, Celina (1996). "Reinventando o poder local: limites e possibilidades do federalismo e da descentralização". São Paulo em Perspectiva, v. 10, n. 3, p. 103-112.

(2001). "Construção e consolidação de instituições democráticas: papel do orçamento participativo". São Paulo em Perspectiva, v. 15, n. 4, p. 1-12,

(2004). "Governos locais e gestão de políticas sociais universais". São Paulo em Perspectiva, v. 18, n. 2, p. 27-41.

SANTOS, Boaventura de Sousa (org.) (2002). Democratizar a democracia. Rio de Janeiro: Civilização Brasileira.

STREETEN, Paul (1982). Fronteras de los estudios sobre el desarrollo. México: Fondo de Cultura Económica.

SZTOMPKA, Piotr (1998). "A história como produto humano: a teoria da agência em desenvolvimento", em A sociologia da mudança social. Rio de Janeiro: Civilização Brasileira.

UL HAQ, Mahbub (1978). A cortina da pobreza: opções para o terceiro mundo. São Paulo: Nacional. 
VEIGA, José Eli da (2011). "Duplo impasse”. Folha de S. Paulo, São Paulo, 30 jul. Caderno A, p. 3.

WANDERLEY, Fernanda (2010). “A arquitetura político-institucional das desigualdades na Bolívia”, em CATTANI, Antonio D. (org.). Riqueza e desigualdade na América Latina. Porto Alegre: Zouk.

\section{Resumo}

Os Relatórios do Desenvolvimento Humano (RDHs) encomendados, anualmente, pelo Programa das Nações Unidas para o Desenvolvimento (PNUD) têm construído, ano a ano, um conjunto de sugestões que visam incentivar os governantes, a sociedade civil, os movimentos sociais e os poderes privados (lideranças econômicas, de modo geral) a buscarem formas de decisão descentralizadas e verticalizadas. Este artigo demonstrará, por meio de uma pesquisa documental, quais são as propostas dos RDHs da década de 2000 para fortalecer procedimentos políticos que corroborem não somente as ações políticas locais mas também a geração de rendas e recursos capazes de impulsionar o desenvolvimento humano, entendido como fortalecimento das capacidades e das oportunidades de construção de melhorias sociais, econômicas e políticas.

Palavras-chave: desenvolvimento humano; poder local; descentralização.

\section{Abstract}

Each year, the Human Development Reports (HDRs) commissioned annually by the United Nations Program Development (UNDP) build a number of suggestions aimed at encouraging governments, civil society, social movements, private powers (economic leaders in general) to seek ways to make decentralized and vertically integrated decisions. This article will demonstrate, through documentary research, what the proposals of the HDRs of the 2000s are to strengthen political procedures that corroborate not only local political actions, but also generation of income and resources capable of promoting human development, understood as strengthening capabilities and opportunities for social, economic and political improvements.

Keywords: human development; local government; decentralization.

Recebido em 30 de maio de 2013.

Aprovado em 9 de setembro de 2013. 